\title{
Uma análise do gênero denúncia à luz do paradigma das Tradições Discursivas
}

\author{
Ticiane RODRIGUES (D) \\ Universidade Federal do Ceará (UFC)
}

\section{○ \\ OPEN ACCESS \\ EDITADO POR \\ - Valéria Severina Gomes (UFRPE) \\ - Aurea Zavam (UFC) \\ - Konstanze Jungbluth (EUV)}

AVALIADO POR

- Arivaldo Sacramento de Souza (UFBA)

- Leonardo Lennertz Marcotulio (UFRJ)

DATAS

- Recebido: 29/10/2020

- Aceito: 27/11/2020

- Publicado: 17/12/2020

\section{COMO CITAR}

Rodrigues, T. (2020)

Uma análise do gênero denúncia à luz do paradigma das Tradições Discursivas. Revista da Abralin, v. 19, n. 3 , p. $676-698,2020$.
RESUMO

O presente trabalho objetiva descrever e analisar categorias linguísticas e discursivas que apontam traços de reelaboração na peça introdutória dos processos-crimes registrados no estado do Ceará nos séculos XX e xxi. O corpus da pesquisa é constituído por denúncias, parte introdutória dos processos-crimes, os quais se encontram abrigados no Arquivo Público do Estado do Ceará (APEC). Para o desenvolvimento da análise, utiliza-se o arcabouço teórico das Tradições Discursivas a fim de observar a repetição de um texto ou de formas textuais que possam ser tomadas como tradições discursivas para, então, descrever traços significativos de reelaboração do gênero. Para melhor chegar aos resultados de análise, optou-se por aplicar alguns princípios relativos à compilação de corpora, para isso, utiliza-se uma das ferramentas computacionais de análise disponíveis, o concordanciador AntConc 3.4.3w. Nesse sentido, servem de base teórica os estudos de Kabatek (2001, 2006), Koch (1997) e Koch e Oesterreicher (2007). Fazendo um recorte da proposta teórico-metodológica de Zavam (2009), esta investigação focaliza a análise em uma categoria que trata da materialidade dos elementos linguísticos e discursivos empregados. Os resultados alcançados revelam que o gênero denúncia apresenta em sua composição traços do que se caracteriza como reelaboração interna, que é uma mudança ocorrida no interior do próprio gênero. Tal constatação evidencia que entre os dois séculos analisados, o gênero apresenta sinais de uma possível reelaboração devido às exigências de suas práticas sociais, como é o caso das informações apuradas para compor a acusação do réu e que são fundamentais para que se instaure a denúncia. 


\section{REVISTA DA ABRALIN}

\section{ABSTRACT}

The present work aims to describe and analyze linguistic and discursive categories that point to re-elaboration traces in the introductory piece of the criminal proceedings registered in the state of Ceará in the 20th and 21st centuries. The research corpus consists of denunciations, an introductory part of the criminal proceedings, which are housed in the Public Archives of the State of Ceará (APEC). For the development of the analysis, the theoretical framework of the Discursive Traditions is used in order to observe the repetition of a text or textual forms that can be taken as discursive traditions to then describe significant features of the genre reworking. To better arrive at the results of the analysis, it was decided to apply some principles related to the compilation of corpora, for that, one of the computational analysis tools available is used, the concordant AntConc 3.4.3w. In this sense, the studies of Kabatek (2001, 2006), Koch (1997) and Koch and Oesterreicher (2007) serve as a theoretical basis. Making a cut of the theoretical-methodological proposal of Zavam (2009), this investigation focuses the analysis in a category that deals with the materiality of the linguistic and discursive elements used. The results achieved reveal that the complaint genre has in its composition traces of what is characterized as internal rework, which is a change that occurred within the genre itself. Such finding shows that between the two centuries analyzed, the gender shows signs of a possible reworking due to the requirements of its social practices, as is the case of the information obtained to compose the defendant's accusation and which are fundamental for the initiation of the complaint.

\section{PALAVRAS-CHAVE}

Tradições discursivas. Gêneros jurídicos. Reelaboração de gêneros.

\section{KEYWORDS}

Discursive traditions. Legal genres. Genre rework.

\section{Introdução}

A língua pode ser concebida como o resultado da interação entre homem e realidade social que carrega em si uma produção sócio-histórica que não se traduz como instrumento, mas como ação que modifica e que transforma. Dessa forma, o estudo da língua não pode estar longínquo da 


\section{REVISTA DA ABRALIN}

sociedade que a produz, uma vez que os processos que a constituem são histórico-sociais. Não por acaso, as variações que ocorrem na língua são percebidas nos gêneros que se reelaboram, se mesclam, ou simplesmente se adaptam às novas necessidades exigidas pela sociedade. Pensando nessa necessidade de inovação linguística, investigamos as transformações ocorridas no gênero denúncia, a peça introdutória do processo-crime responsável por dar início ao processo criminal.

Em nossa pesquisa, o objetivo geral é a análise de exemplares do gênero denúncia, abrigados no Arquivo Público do Estado do Ceará (APEC) o qual buscamos, numa perspectiva diacrônica, contemplar-lhe as formas linguísticas que o caracterizam. Para avançarmos rumo aos nossos objetivos, utilizamos fundamentalmente o paradigma das Tradições Discursivas (doravante TD), para então procedermos à observação da composição das TD no referido gênero com o intuito de descrever vestígios significativos de mudança e/ou permanência que contribuíram para sinalização de uma possível reelaboração no gênero praticado na esfera do judiciário cearense.

Justificamos a importância de nossa pesquisa dentro do campo em que nos inserimos tendo como base que a noção de TD vem conquistando estatuto privilegiado nos estudos da linguagem desde a última década, notadamente, nas pesquisas em Linguística Histórica, pelo subsídio dado a essa área, especificamente, no que se refere à representatividade do corpus. Desse modo, a seleção de textos baseada na distinção de TD é uma via de acesso, não a única, para a pesquisa que envolve mudança e/ou variação (seja da língua ou do texto), visto que, em razão da temática, das finalidades comunicativas do produtor e das demais condições gerais da produção dos enunciados, as TD predispõem o uso, a frequência e a distribuição de determinadas construções linguísticas. É pela observação de determinados fenômenos que existem textos mais propícios a apresentarem variação ao passo que outros textos não revelam tanto a mesma relevância à investigação de um tipo de fenômeno linguístico específico.

Ressaltamos que levamos em consideração os estudos da Diplomática que em muito tem contribuído para o debate sobre a autenticidade documental uma vez que esta ciência

ocupa-se da estrutura formal dos atos escritos de origem governamental e/ou notarial. Trata-se, portanto, dos documentos que, emanados das autoridades supremas, delegadas ou legitimadoras (como é o caso dos notários), são submetidos, para efeito de validade, à sistematização imposta pelo Direito (BELLOTTO, 2002, p. 8)

Surgida como uma disciplina concreta ainda no século XVI, a Diplomática originou-se para lidar com as questões da falsificação e das dúvidas em torno da autenticidade de documentos medievais. Nos tempos atuais, seus estudos concentram-se na gênese, na constituição interna dos documentos, bem como na transmissão e na relação desses documentos entre seu criador e seu próprio conteúdo. Desse modo, não se objetiva simplesmente averiguar a autenticidade formal dos documentos como na época de seu surgimento, mas identificar, avaliar e demonstrar a verdadeira natureza que os compõem.

A partir da concepção da Diplomática como eixo de estudo, tomou-se o documento diplomático como o registro legitimado do ato administrativo ou jurídico. Logo, esse documento pode ser tido como uma espécie de testemunho escrito de natureza jurídica, redigido com observância a certas formas estabelecidas que se destinam a dar-lhe a força probatória necessária. Sendo assim, a 


\section{REVISTA DA ABRALIN}

estrutura formal do documento torna-se o objeto central da Diplomática e como especificidade dessa estrutura sua construção semântica será obrigatório, pois cabem dados fixos que ocorrerão em todos os documentos que utilizaram como veículo a mesma espécie documental e os dados variáveis pertencentes a cada documento da mesma espécie documental.

Cabe aqui, mesmo que superficialmente, a distinção entre tipologia e espécie documental. Como já mencionado, a Diplomática se ocupa da configuração interna do documento, do estudo jurídico de suas partes e dos caracteres necessários para que se atinja sua autenticidade. Por sua vez, a tipologia documental, além de se preocupar com as questões internas do documento também se preocupa em estudá-lo enquanto integrante da mesma série documental que se origina da junção de documentos correspondentes à mesma atividade. Em outras palavras, o tipo documental é a especificidade que qualifica a espécie de documento de acordo com a atividade ou função do documento que a gerou. Por outro lado, a espécie documental é a configuração que assume um documento de acordo com a disposição e a natureza das informações nele contidas, seria, portanto, o aspecto formal de um documento que obedece a fórmulas convencionadas, estabelecidas pelo Direito administrativo ou notarial.

A opção pelo gênero peça introdutória do processo criminal para fundamentar empiricamente o trabalho não se justifica aleatoriamente, pois se trata de um documento que circula na esfera judiciária há bastante tempo e sobre ele projeta-se a imagem de um gênero com estruturas formais rigidamente pré-estabelecidas. Acreditamos, portanto, que se trata de um gênero em que a reelaboração se dê de forma mais lenta, em outro compasso, como queremos crer, se compararmos, por exemplo, com gêneros da esfera jornalística.

Como gênero, a peça inaugural do processo-crime, a exemplo de qualquer outro, estabelece relação com outras formas textuais, presentes na memória cultural das sociedades em que circulam, e, como tradição discursiva, é possível que tenha influência de outras línguas, e que essa interferência se manifeste através da adoção de elementos no nível da língua, da forma, do conteúdo e do discurso.

Nossa pesquisa tem como objetivo, além de demonstrar que algumas estruturas linguísticas são mais ou menos recorrentes na composição de determinado gênero textual, com base em categorias linguístico-discursivas, reconhecer e analisar expressões que venham servir de identificadores do gênero.

Realizamos um levantamento de formas textuais que podem ser tomadas como tradições discursivas dentro da peça inaugural do processo-crime ao longo do século XX até o início do século XXI. Para isso, o corpus da pesquisa é constituído de 46 exemplares da peça introdutória de processos-crime, crimes estes de natureza distintas, registrados no Estado do Ceará, no século XX. Para contrastar com a amostra referente ao século XX, também colhemos alguns exemplares do século XXI que se encontram no sítio do Ministério Público do Estado do Ceará (MPCE).

Para melhor chegarmos aos nossos resultados de análise, optamos por aplicar alguns princípios relativos à compilação de corpora, para isso, usamos uma das ferramentas computacionais de análise disponíveis, o concordanciador AntConc 3.4.3w¹. Por essa razão e, por ter sido muito útil em nossa

\footnotetext{
${ }^{1}$ Disponível gratuitamente em: http://www,antlab.sci.waseda.ac.jp/software.html
} 


\section{REVISTA DA ABRALIN}

pesquisa, detalharemos, neste artigo, a contribuição dada por essa ferramenta para que chegássemos aos resultados almejados.

\section{Discutindo o conceito de Reelaboração de Gêneros}

Em nossa pesquisa, temos como objeto de investigação exemplares do gênero discursivo peça inaugural do processo criminal, concebidos como denúncia, datados do século XX e algumas amostras concebidas no século XXI. Para isso, baseamo-nos em Bakhtin ([1979] 2011) no que se refere ao conceito de reelaboração, com o intuito de tecermos nossa observação acerca dos vestígios de mudança e/ou permanência do gênero em foco.

Com Bakhtin, tomamos conhecimento da noção desse fenômeno chamado reelaboração nos gêneros $^{2}$. De acordo com as transformações pelas quais as sociedades passam, os gêneros que nelas circulam podem acompanhar tais mudanças e, assim, podem desaparecer ou migrar para outros gêneros, passar por um contínuo processo de reelaboração, intercalação. Sabemos que esse é um processo natural quando se trata de algo que está em constante dinamismo dentro de uma sociedade.

Contudo, a "reestruturação e renovação dos gêneros" (BAKHTIN, 2011, p. 286) de que fala o autor não ocorre sem que delas não nos apercebamos, pois é comum que elas deixem seus rastros como pistas dessa transformação. Segundo Bakhtin (2005, p. 106, grifo do autor), “o gênero sempre é e não é o mesmo, sempre é novo e velho ao mesmo tempo. [...] O gênero vive do presente, mas sempre recorda seu passado, o seu começo". É por meio dessa recordação que é possível encontrar, de alguma forma, indícios do processo de reelaboração pela qual um gênero passou.

O termo reelaborar foi empregado por Bakhtin para falar da transformação pela qual os gêneros primários, aqueles correspondentes aos gêneros simples ou do cotidiano, passam ao serem inseridos nos chamados gêneros secundários, que são os complexos, mais elaborados.

A principal diferença entre eles é que os primários são produzidos onde cada esfera da atividade humana se realiza, materializando-se em seu contexto específico, sendo mais comum no registro oral da língua, como é o caso da conversação informal face a face ou dos bilhetes pessoais, informais. Os secundários, por sua vez, são desenvolvidos com base em um convívio cultural mais formalizado, e são, geralmente, produzidos na modalidade escrita da língua.

Depois de realizada a distinção acerca do que seria gênero primário e secundário, Bakhtin afirma que

Durante o processo de sua formação, esses gêneros secundários absorvem e reelaboram os gêneros primários (simples) de todas as espécies, que se constituíram em circunstâncias de uma comunicação verbal espontânea. Os gêneros primários, ao se tornarem componentes dos gêneros secundários,

\footnotetext{
${ }^{2}$ Ressaltamos que o termo reelaboração aparece na edição traduzida do original em russo por Paulo Bezerra. Em edições anteriores traduzidas da versão em francês, o termo correspondente é transmutar.
} 


\section{REVISTA DA ABRALIN}

transformam-se dentro destes e adquirem uma característica particular: perdem sua relação imediata com a realidade existente e com a realidade dos enunciados alheios [...]. (BAKHTIN, 2011, p. 281)

A partir dessa afirmação, concordamos com Zavam (2009) ao entender a reelaboração como um processo constituinte dos gêneros, pois nenhum gênero, sendo ele primário ou secundário, permanece inalterável no decorrer de suas manifestações, pois sobre ele recaem as mudanças sociais, culturais, históricas e ideológicas pelas quais passam a sociedade de um modo geral. Mais uma vez, devido ao pensamento bakhtiniano, nos vemos diante do fato de que existe uma relação estreita entre a história da sociedade e a história dos gêneros discursivos.

Zavam (2009, p. 50) discute a reelaboração dos gêneros em sua tese de doutoramento e sobre esse fenômeno diz que

\footnotetext{
Quando um gênero absorve e transmuta ${ }^{3}$ outro, está concomitantemente transmutando-se também. Assim, o romance (da "esfera dos sistemas ideológicos constituídos".), ao tomar a carta (da "esfera da ideologia do cotidiano") como componente, para nos valermos do exemplo de Bakhtin, transforma não só a carta, que passa a integrar uma nova realidade, mas também a si próprio, que passa a exibir uma nova forma composicional.
}

Pensando nos problemas advindos da exploração de um conceito ainda tão pouco explorado, Zavam (2009, p. 54-55), depois de travar diálogo com a tese de Araújo (2006), que busca em sua pesquisa explicar a transmutação ${ }^{4}$ operada no gênero chat, e baseando-se na noção de transmutação de Bakhtin, evidencia a transmutação como elemento constitutivo dos gêneros e, para isso, destaca três proposições inerentes à manifestação do fenômeno, que em linhas gerais seriam:

\footnotetext{
$1^{\circ}$ ) O gênero incorporado (ou transmutado) é agregado à estrutura composicional do gênero incorporante (ou transmutante):

$2^{\circ}$ ) O gênero incorporante transmuta e é transmutado;

$3^{\circ}$ ) O gênero incorporado e o gênero incorporante podem fazer parte tanto de esferas diferentes quanto de uma mesma esfera. (ZAVAM, 2009, p. 54-55).
}

Segundo a mesma autora, "o gênero conserva, em sua estrutura composicional, tema e/ou estilo $^{5}$, marcas da transmutação, que podem ser percebidas em sua história, isto é, que podem recordar o seu passado, recente ou remoto." (ZAVAM, 2009, p.55). É com base nesse aspecto de conserva ção da estrutura composicional que observaremos ser possível a análise dos traços de mudança ocorridos na peça introdutória dos processos criminais.

\footnotetext{
${ }^{3}$ Zavam (2009) adota o termo transmutar entendendo-o como o processo de reelaboração de que estamos falando, por ter trabalhado com a edição de Estética da criação verbal, de 2000, traduzida do francês por Maria Ermantina G.G. Pereira, quando não havia sido publicada a versão por Paulo Bezerra, que é de 2011.

${ }^{4}$ Araújo (2006), assim como Zavam (2009), trabalhou com a edição traduzida do francês.

${ }^{5}$ Aqui tomamos o gênero em sua totalidade assim como propôs Bakhtin (2011)
} 


\section{REVISTA DA ABRALIN}

\section{O paradigma da Tradição Discursiva}

A noção de tradição discursiva (TD) é um paradigma teórico que se apresenta como um elo fértil entre a história da língua e a história dos textos e da história social. As TD surgiram no âmbito da Filologia Românica alemã, mais especificamente dentro dos estudos de mudança e permanência linguística de Eugenio Coseriu entre as décadas de 1950 e 1970. Seguindo a linha de Coseriu, trazemos como base para fundamentar nosso diálogo acerca das TD, autores precursores como Peter Koch (1997) e Johannes Kabatek (2001; 2006). O termo tradição discursiva nos remete aos modos de dizer que se tornam uma tradição em uma determinada cultura devido a sua repetição.

Tomados na perspectiva das TD, os textos compreendem conjuntos de enunciados linguísticos que se relacionam a uma realidade, a uma situação e a todos os outros textos já enunciados. Tais textos apresentam o que chamamos de tradicionalidade, que reside no fato de se repetir completa ou parcialmente quaisquer aspectos temáticos, de forma e/ou de conteúdo de um texto enunciado anteriormente produzido. Para exemplificar o que se afirma, apresentamos a seguir dois textos, o primeiro de uma revista científica da área de Linguística e o segundo extraído de Longhin (2014): um resumo de artigo científico e um boletim de ocorrência policial.

Este artigo apresenta uma pesquisa a respeito de crenças linguísticas feita com falantes escolarizados de Fortaleza, bem como uma apresentação teórica prévia do assunto, a partir de estudos da Sociolinguística. Foram entrevistadas seis pessoas e feitas dez perguntas a cada uma. As perguntas enfocam questões como o falar das diferentes classes socioeconômicas, o falar regional de Fortaleza e as diferenças nos modos de falar que os falantes percebem. Os resultados, ainda que iniciais, devido a pouca quantidade de entrevistados, mostram que muitas crenças a respeito da língua estão presentes no pensamento das pessoas.

TEXTO 1 - Resumo de artigo científico

Fonte: Extraído de Entrepalavras, Fortaleza - ano 1, v.1, n.1, p. 25, ago/dez 2011 


\section{REVISTA DA ABRALIN}

Foi repassado na rede de rádio que havia a necessidade de uma guarnição policial no Hotel Prive a fim de dar apoio aos militares do policiamento velado da $6^{\text {a }}$ Cia. De acordo com o PM, através de denúncia anônima ficaram sabendo que havia um casal hospedado no quarto nr. 17 daquele hotel e que pelas suas atitudes suspeitas poderiam estar com alguma transação ilícita (drogas), uma vez que foram observadas várias pessoas que entraram no hotel e se dirigiam para o quarto nr. 17 e após o contato estas pessoas saíam rapidamente. O policiamento velado da $6^{\text {a }}$ Cia. sabendo da situação se dirigiu até o hotel e foi ter com os ocupantes do referido quarto. Foi procedida uma vistoria no local onde os objetos e pertences foram revistados sendo que foram encontrados drogas e dinheiro. A droga estava bem embalada e o dinheiro com cédulas de diversos valores. Em tempo, o segurança do referido hotel disse que o recinto é equipado com circuito interno e que foram vistas várias pessoas adentrando ao hotel e se dirigindo até o aludido quarto nr. 17 onde entravam e após alguns segundos saíam rapidamente. [Boletim de ocorrência produzido na cidade de Belo Horizonte.]

TEXTO 2 - Boletim de ocorrência policial Fonte: Longhin (2014, p. 11)

Nos dois exemplos acima, temos dois modelos textuais que seguem TD por estarem em relação de repetição e variação com vários outros textos similares anteriormente escritos ou ditos, em contextos e com propósitos comunicativos semelhantes. Logo, tanto o resumo quanto o boletim de ocorrência apresentam similaridades com outros resumos científicos e outros boletins policiais, cada qual em suas respectivas esferas de circulação. Isso é o que condiz com a tradicionalidade aludida anteriormente, que se refere a essas repetições da qual fazemos uso ao nos reportarmos a um modelo textual já conhecido.

O conceito de tradição discursiva surgiu no âmbito dos estudos da Filologia Pragmática alemã, na década de 1980. Mais pontualmente, esse conceito parte das concepções de linguagem como uma atividade criadora e mudança linguística desenvolvida pelo linguista romeno Eugenio Coseriu, para quem a língua é vista como um sistema em movimento, em permanente sistematização. Nesse sentido, o linguista romeno propõe que a linguagem seja como

[...] uma atividade humana universal que se realiza individualmente, mas sempre segundo técnicas historicamente determinadas ("línguas"). Com efeito, todos os seres humanos adultos e normais falam e, em certo sentido, falam, sempre [...]. Por outro lado, todo falante fala individualmente (mesmo no diálogo): a linguagem não é nunca atividade "coral". Por fim, a linguagem se apresenta como historicamente determinada, como "língua" (italiano, português, francês, alemão, etc.); não há falar que não seja falar uma língua. (COSERIU, 1980, p. 91, grifos do autor).

A partir dessa noção, Coseriu concebeu os três níveis de fala, que inspiraram o surgimento das tradições discursivas. O primeiro nível diz respeito ao nível universal, que é o falar em geral; o segundo é o nível histórico das línguas; e o terceiro, é o nível individual de textos ou discursos concretos. Os três níveis são coexistentes, uma vez que não se pode falar sem utilizar uma língua e sem gerar um texto (KABATEK, 2006). 


\section{REVISTA DA ABRALIN}

A cada um dos níveis referidos acima corresponderia um ponto de vista que pode ser resumido no seguinte quadro extraído de Coseriu (1980, p. 93):

\begin{tabular}{|c|c|c|c|}
\hline níveis $\underbrace{\text { pontos de }}_{\text {vista }}$ & $\begin{array}{l}\text { Évé } \rho \gamma \in \omega \alpha \\
\text { atividade }\end{array}$ & 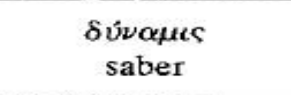 & $\begin{array}{l}\text { éprov } \\
\text { produto }\end{array}$ \\
\hline rível universal & falar em geral & saber elocucional & $\begin{array}{l}\text { totalidade do } \\
\text { "falado" }\end{array}$ \\
\hline nível histórico & língua concreta & saber idiomático & (língua abstrata) \\
\hline nível individual & discurso & saber expressivo & "texto" \\
\hline
\end{tabular}

QUADRO 1 - Estrutura geral da linguagem Fonte: Coseriu (1980, p. 83)

O nível universal refere-se à língua como instrumento que permite ao homem se comunicar, independentemente do idioma que esteja sendo empregado, trata-se da atividade do falar; do ponto de vista da competência, refere-se ao falar em geral, concebido como o saber elocucional, que diz respeito ao conhecimento das coisas; e do ponto de vista do produto, trata-se da totalidade dos enunciados.

O nível histórico diz respeito à língua como sistema de significação historicamente dado, a língua concreta, particular; do ponto de vista da competência, corresponde ao saber idiomático que se refere ao conhecimento das regras, formas e conteúdos de uma determinada língua; e quando se trata do produto, refere-se à língua abstrata, que podemos entender como a língua objetivada pelas gramáticas e dicionários.

Por fim, o nível individual corresponde ao discurso ou texto como enunciação particular e única, figurando, concomitantemente, como expressão da capacidade universal da fala e de uma tradição histórico-cultural; o saber expressivo abarca o conhecimento de uma situação de fala determinada; e como produto trata-se do texto em qualquer que seja a modalidade, oral ou escrita.

De forma sumária, esses três níveis se fazem presentes sempre que alguém fala, quando um determinado enunciador dirige-se ao interlocutor com uma determinada intenção comunicativa, por exemplo, numa situação corriqueira quando duas pessoas encontram-se e iniciam um diálogo. Primeiro, temos o nível universal, uma vez que as pessoas envolvidas na conversa utilizam-se de uma atividade inerente a todos os homens, o falar. Segundo, temos o nível histórico, pois os falantes utilizam um mesmo idioma. E, por último, temos o nível individual que corresponde a uma utilização concreta e particular que é feita no momento em que o(s) indivíduo(s) fala(m).

Foi fundamentado nessa noção dos três níveis de fala que filólogos romanistas alemães retomaram a concepção de tradição discursiva de Coseriu e a integraram ao sistema de estrutura geral da linguagem, mais precisamente no nível histórico.

Para Koch (1997), tanto a história dos textos quanto a história das línguas se encontrariam abrigadas no segundo nível proposto por Coseriu, que seria o nível histórico. Assim, Koch propõe, 


\section{REVISTA DA ABRALIN}

baseado nos postulados de Coseriu e Schlieben-Lange, a bipartição do nível histórico, acrescentando, ao lado da história da língua, a história das tradições discursivas. Nas palavras dele:

Considero, portanto, indispensável duplicar o modelo de Coseriu no nível histórico. Paralelamente, ou melhor, dizendo: transversalmente às tradições e normas intralinguísticas, devem ser colocadas também as tradições textuais ou - como as denomino - as tradições discursivas ou normas discursivas. (KOCH, 1997, p. 03)

Desse modo, o nível histórico que foi bipartido passaria a responder por duas dimensões: a língua como sistema, abrangendo a gramática e o léxico; e a tradição discursiva, com o texto. Para esclarecer e melhor visualizar, segue o quadro retirado de Koch (1997):

\begin{tabular}{|c|c|c|}
\hline NÍVEL & DOMÍNIO & TIPO DE REGRAS \\
\hline Universal & atividade de falar & regras do falar \\
\hline Histórico & línguas particulares & regras da língua particular \\
\cline { 2 - 3 } & tradição discursiva & regras discursivas \\
\hline Individual/atual & Discurso & \multicolumn{1}{|c}{} \\
\cline { 2 - 3 } & &
\end{tabular}

QUADRO 2 - A reduplicação do nível histórico coseriano Fonte: Koch $(1997,03)$

Com a bipartição do nível histórico, temos as seguintes projeções: a língua como sistema, em que se abriga a gramática e o léxico, e a tradição discursiva em que se encontra o texto. Podemos dizer que o nível histórico foi subdividido a fim de esclarecer o fato de que as línguas particulares não devem ser confundidas com tradições discursivas, mesmo que ambas sejam tradições históricas.

No campo das línguas particulares, encontramos as regras inerentes a cada língua particular, isto é, regras intralinguísticas que tratam dos aspectos, por exemplo, morfológicos, fonológicos, sintáticos como é o caso das regras do português, espanhol, francês etc. Quando um indivíduo qualquer, falante do português, sabe que o determinante deve concordar com o nome ao qual se refere como em A menina era a única que se importava com o pai, ele está se valendo de regras idiomáticas de uma língua histórica particular.

Quanto às tradições discursivas, estas dizem respeito tanto às formas textuais típicas quanto aos gêneros discursivos, por exemplo, quando um falante, ao escrever uma carta, a inicia com a fórmula Fortaleza, 15 de julho de 2015, ele recorre neste momento a regras discursivas estabelecidas pelas similaridades com outros textos de mesma finalidade comunicativa, no caso, os textos epistolares. Logo, sabemos que se trata de saberes distintos, pois um não pressupõe o outro, necessariamente, mas ambos são historicamente determinados.

Portanto, de acordo com Longhin (2014), na esfera dos textos, sua historicidade está no acervo de textos já ditos e escritos, armazenados na memória da comunidade, na forma de modelos linguísticos tradicionais e tal acervo, sempre que mobilizado nas situações de enunciação, requer a repetição de elementos tradicionais, trazendo-os novamente para a cena. A construção do enunciado se faz a partir da conjunção inédita entre os textos previamente estabelecidos que são evocados e 


\section{REVISTA DA ABRALIN}

repetidos total ou parcialmente, com a novidade da situação que permite que toda nova enunciação seja um evento único.

\section{O programa AntConc e sua contribuição na análise de dados}

Para que pudéssemos chegar melhor aos nossos resultados de análise, optamos por aplicar alguns princípios relativos à compilação de corpora, para isso, decidimos usar uma das ferramentas computacionais de análise disponíveis, o concordanciador AntConc 3.4.3w

As ferramentas que são utilizadas para a análise de corpora têm, nos dias atuais, em estudos linguísticos, um papel bastante importante. Apesar de tais ferramentas terem por base um critério tão somente quantitativo, os dados obtidos são de grande valia para uma análise qualitativa, pois ajudam a perceber variáveis distintas, além de possibilitar um olhar mais aguçado sobre o fenômeno investigado.

Tendo em vista nossos objetivos, escolhemos a ferramenta AntConc por se tratar de um software livre e que tem a vantagem de ser leve, além de dispensar a instalação, o que facilita o manuseio para pesquisadores/usuários iniciantes. Percebemos que, por meio de seu uso, pudemos proceder à análise de modo mais preciso quanto à identificação de determinados termos e expressões (palavras ou frases), uma vez que o programa permite buscas e faz o cálculo estatístico de ocorrência de palavras em seu modo contextualizado.

Desenvolvido por Lawrence Anthony, da Universidade de Waseda, no Japão, o AntConc é um freeware que está disponível para download e apresenta versões para os sistemas Windows, Linux e Mac. De modo resumido, o AntConc é um concordanciador que é utilizado para listar as ocorrências de uma determinada palavra ou frase em uma quantidade definida de contextos, para possibilitar buscas e fazer o cálculo estatístico das palavras em um corpus escrito.

De acordo com Alberts-Franco (2015, p. 186-187), o AntConc é:

\footnotetext{
um programa escrito em Perl 5.8 utilizando o editor de texto ActiveState Komodo e roda em qualquer ambiente Windows, bem como em Macintosh OSX e Linux. As ferramentas que compõem o AntConc são: Concordance; Concordance Plot; File View; Clusters; Collocates; Word List e Keyword List. Concordance gera linhas de concordância de um determinado termo a partir dos textos analisados pelo pesquisador. Concordance Plot é um gráfico, semelhante a um "código de barras", que mostra a distribuição, no arquivo em questão, do termo que se está pesquisando. File View localiza, no arquivo com o qual se trabalha, as diferentes ocorrências do termo pesquisado. Clusters gera uma lista do termo que se pesquisa em ordem ou de frequência, alfabética, de probabilidade ou de suas terminações. Collocates gera uma lista ordenada das palavras próximas ao termo pesquisado. Word List gera uma lista, ou em ordem alfabética ou por frequência, de todas as palavras que constam dos arquivos selecionados
}

\footnotetext{
${ }^{6}$ Disponivel gratuitamente em: http://www.antlab.sci.waseda.ac.jp/software.html
} 


\section{REVISTA DA ABRALIN}

para a análise linguística. Por fim, Keyword List gera uma lista de palavras-chave comparando-se a frequência das palavras do corpus de estudo com a frequência das palavras do corpus de referência.

Para nosso objetivo, o programa cumpriu bem seu papel e ajudou na nossa análise do corpus. Uma das maiores comodidades para se utilizar esta ferramenta é que após fazer o download do arquivo não é necessário instalá-lo.

Buscamos em nossa pesquisa expressões que possam se configurar como tradições discursivas e possam dar indícios de uma possível reelaboração do gênero denúncia, peça inaugural do processo criminal. Para que consideremos uma expressão como TD, é necessário que esta mesma expressão seja evocada e repetida diante de determinada cena enunciativa; por isso o contexto em que as formas textuais aparecem é fundamental.

O uso desta ferramenta se torna útil tanto para a coleta quanto para a análise de nossos dados, uma vez que a interface do programa é simples e, em uma mesma janela, é possível navegar por diferentes opções de análise. O que mais chamou nossa atenção para a utilização dessa ferramenta em nosso estudo reside no fato de que observamos o contexto em que determinadas expressões se repetem e, consequentemente, se configuram como uma tradição discursiva.

Embora não exclua o trabalho manual, o concordanciador facilita e permite um trabalho mais pontual no trato do corpus, já que pode ser programado para eliminar elementos que não interessem ao pesquisador.

\section{Discussão e análise de dados: as expressões e as tradições discursivas da denúncia}

A Linguística, como sabemos, se caracteriza por não ser uma ciência pronta, tampouco definitiva, mas que está em constante evolução, com novas perspectivas de análise, novos paradigmas e novos olhares. Sob esta perspectiva, lançamos nosso olhar para uma categoria específica de texto redigido dentro da esfera jurídica. O tratamento linguístico que os operadores da Justiça dão aos processos criminais e, ainda, a forma como estes textos são percebidos por quem os produz e por quem os recebe são alvo de investigação dentro da área da Linguística. Enfim, são múltiplos os segmentos que podemos considerar quando se trata da análise de gêneros.

Com o intuito de tornar nosso percurso analítico mais claro e objetivo, elaboramos um esquema para melhor mostrar como se deu nossa investigação, que cobriu aspectos ligados ao entorno discursivo e à materialidade textual, propriamente dita: 


\section{REVISTA DA ABRALIN}

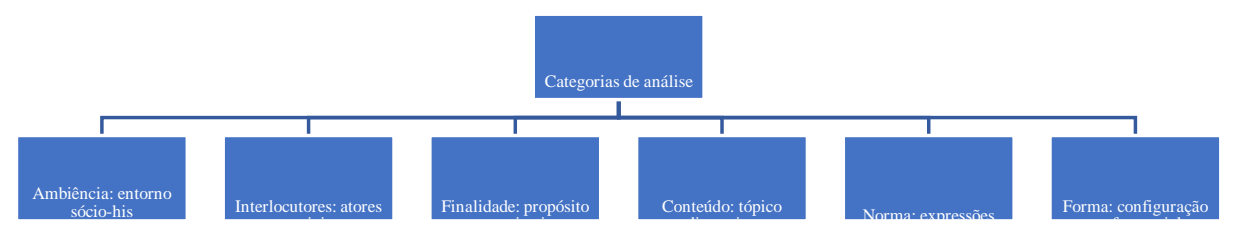

FIGURA1 - Categorias de análise

Fonte: Elaboração própria

Em nosso estudo, focalizamos a categoria da Norma, pois contempla os elementos linguísticos e discursivos mais abrangentes e previsíveis no gênero. A Norma, quando associada à realização de elementos em um contexto coletivo, está diretamente ligada às tradições presentes em uma determinada sociedade, deixando mais evidente o que é utilizado pelos falantes de forma mais regular. Dessa forma, analisaremos as expressões, isto é, as formas textuais de abertura e fechamento que compõem as tradições discursivas do gênero denúncia.

É interessante comentarmos a respeito do tipo de linguagem que encontramos nos textos d9o nosso corpus, uma vez que se trata de um gênero pertencente à esfera comunicativa jurídica. A linguagem, como sabemos, é o lugar de interação humana, é por meio dela que é possível realizar a interação comunicativa pela produção de efeitos de sentido entre os interlocutores, em uma dada situação de comunicação, que por sua vez se insere em um contexto sócio-histórico e ideológico previamente estabelecido. De acordo com Possato (2012, p. 99),

\footnotetext{
a palavra permeia todos os nossos atos, em todas as instâncias da realidade social, forma-se em todo setor do conhecimento humano uma linguagem e, consequentemente, um diálogo particular. À medida que aumenta o grau de especialização de um determinado conhecimento, o vocabulário técnico também se especializa, aumentando a distância entre o diálogo dos iniciados nesse conhecimento e dos não iniciados. Podemos dizer que temos o idioma - a Língua Portuguesa - e os subidiomas de cada área de conhecimento produzindo e alimentando particularidades terminológicas. Dentre esses subidiomas, no Brasil, destaca-se a linguagem jurídica devido à fascinação exercida pela atividade profissional jurídica, atividade reconhecida como espaço de extremo poder.
}

É dentro desse contexto que nosso corpus está situado, uma vez que o produtor das denúncias, sendo um profissional da área jurídica, portanto, um operador do Direito, utiliza a linguagem especializada que the compete para o exercício de sua profissão. Além disso, de um modo geral, os documentos manuscritos, ou não, que se acumulam nos acervos dos arquivos brasileiros representam uma fonte inesgotável de informações, permitindo a comunicação através do tempo e do espaço. Os documentos revelam a escrita de uma época e esta traz à tona a natureza do texto com seus argumentos, propósitos e intenções, e, também, termos particulares, o léxico próprio da área. 


\section{REVISTA DA ABRALIN}

O corpus da pesquisa é constituído de exemplares da peça introdutória de processos-crime, crimes estes de natureza distintas, registrados no Estado do Ceará, no século XX, os quais se encontram abrigados no Arquivo Público do Estado do Ceará (APEC). Também, colhemos alguns exemplares do século XXI que encontram-se no sítio do Ministério Público do Estado do Ceará (MPCE). O processo-crime, na íntegra, reúne os feitos ou fatos necessários para que um crime possa ser investigado. Retomando o que já foi dito, trata-se de um gênero que abriga diversos outros gêneros, por isso mesmo revela uma expressiva riqueza de elementos capazes de subsidiar pesquisas quer de cunho histórico, quer de cunho linguístico-discursivo, ou mesmo jurídico.

Para a constituição do corpus desta pesquisa, a amostra foi coletada no Arquivo Público do Estado do Ceará (APEC). Essa constituição seguiu os seguintes passos:

i) primeiramente as denúncias foram colhidas e avaliadas de acordo com sua relevância em relação à pesquisa;

ii) em seguida foram fotografadas;

iii) posteriormente foram transcritas, preservando-lhes a grafia original, bem como o sistema de pontuação e as notações encontradas no texto original.

A transcrição utilizada é a semidiplomática, de acordo com Spina (1994, p. 85) aquela que "representa uma tentativa de melhoramento do texto, com a divisão das palavras, o desdobramento das abreviaturas", constituindo-se assim em "uma formas de interpretação do original, pois elimina as dificuldades de natureza paleográfica suscitadas pela escritura. Além disso, Cambraia (2005, p. 95) afirma que esse tipo de transcrição se caracteriza pelo baixo grau de intervenção do editor, sendo, por isso, destinada a um público mais restrito e especializado, entre os quais linguistas, historiadores, antropólogos, e seguiu os sinais e as convenções empregados pela equipe nacional do Projeto para a História do Português Brasileiro - PHPB (cf. Anexo).

Para a realização desta pesquisa, a coleta foi feita a partir de escolhas aleatórias dos processos registrados no Ceará, pois julgamos relevante levarmos em consideração os anos em que os crimes foram praticados e não a tipologia criminal, pois isso limitaria muito a nossa pesquisa. Para isso, utilizamos 46 amostras de denúncias, sendo 41 delas correspondentes ao século XX e apenas 05 que correspondem ao século XXI. Tal diferença se deu por conta de utilizarmos as amostras do presente século apenas para contrastar com as amostras do século passado a fim de verificar as possíveis mudanças e/ou permanências no percurso do gênero. Dividimos o corpus da seguinte maneira:

\begin{tabular}{|c|c|c|}
\hline Fases & Século XX & Século XXI \\
\hline Fase 1 & $1911-1940$ & $2001-2010$ \\
\hline Fase 2 & $1941-1970$ & - \\
\hline Fase 3 & $1971-2000$ & - \\
\hline
\end{tabular}

QUADRO 3 - Distribuição do corpus por período e quantidade Fonte: Elaboração própria 


\section{REVISTA DA ABRALIN}

Reconhecendo a peculiaridade do discurso jurídico, analisamos algumas expressões, tão recorrentes nesse tipo de discurso. Tais expressões, interpretadas à luz do paradigma das tradições discursivas, revelam-se como formas textuais que fazem parte do acervo da memória cultural de uma comunidade, isto é, modos tradicionais de dizer ou escrever. São justamente essas expressões, essas tradições discursivas, que nos permitem reconhecer um gênero, um subgênero ou mesmo uma unidade retórica de um texto/gênero.

Nas denúncias, identificamos como expressões formas de abertura e de fechamento, e também focalizamos as manifestações linguísticas e discursivas presentes nos textos que demonstram a relação texto-sociedade por meio dos usos linguísticos registrados nessa TD que é o gênero denúncia.

As expressões de uso constante nas aberturas e encerramentos das peças têm grande valor histórico porque são usadas convenientemente mediante regras. Os textos jurídicos, em sua maioria, apresentam documentos que apresentam alto grau de fixidez quanto à organização estrutural e formal. Apresentamos como se estrutura formalmente o gênero denúncia com as partes mais relevantes que se organizam não apenas do ponto de vista da estrutura típica do gênero, mas também linguisticamente, dando destaque para as formas textuais que emergem do texto, o léxico, os pronomes de tratamento, o tempo verbal predominante, entre outras.

O juiz, mencionado no vocativo do texto, é a autoridade judicial máxima a quem o texto da denúncia é destinado, é representado por meio de uma forma honrosa que o distingue dos demais atores sociais presentes no gênero: "Ilustríssimo Senhor Doutor Juiz [...]". Como percebemos, há dois pronomes de tratamento que caracterizam uma fórmula textual com a qual se inicia a petição jurídica, os quais evidenciam rigor formal e demonstração de respeito inerente ao procedimento jurídico pelo uso dessa expressão, embora para os não conhecedores da área jurídica, este uso possa soar como exagero, já que apenas um pronome seria suficiente para cumprir a função que lhe cabe no texto.

Chama-nos atenção o fato de o pronome de tratamento empregado ser V.Sa. (Vossa Senhoria), e não V.Exa. (Vossa Excelência), como vemos empregado em textos dessa natureza mais atuais. $\mathrm{O}$ pronome de tratamento V.Sa., empregado para autoridades de um modo geral, nesses textos também é empregado para uma autoridade em particular: Juiz de Direito. Esse dado, também atestado nos outros exemplares do corpus, sinaliza para uma variação no uso do pronome V.Exa., ou uma possível mudança que tenha se operado na forma de dirigir-se aos magistrados.

Após ser referido no vocativo, o juiz passa a ser referenciado em segundo plano nas demais ocorrências. Há um encobrimento do juiz por meio de nominalizações das atividades que cabem a ele realizar, como é o caso da instauração do processo legal, da citação do(a) acusado(a) para comparecer em juízo, da inquirição das testemunhas e da condenação do(a) denunciado(a).

No texto, o promotor faz referência a si mesmo em terceira pessoa, como uma forma de se distanciar do texto. Ele se autorrepresenta, de modo implícito, no texto por meio de expressões como "oferece denúncia", "vem denunciar". "pede-se [...] que se instaure", "que se ouçam[...]". Essa forma de encobrimento de si pode ser devido ao fato de assumir que os leitores, dentro do contexto jurídico em que estão inseridos, têm o conhecimento prévio sobre o agente e, com isso, evita a 


\section{REVISTA DA ABRALIN}

redundância. A sua personalização se dá apenas no momento da assinatura, em que é mencionado seu nome e sobrenome, seguido de sua função, Promotor de Justiça.

Há a tendência em usar a terceira pessoa do discurso à primeira. Pensamos ser uma forma de mostrar polidez e soar menos pretensioso em sua petição, uma vez que ele está falando em nome do órgão que está representando e o que se pretende é alcançar êxito e obter a condenação do réu, tentando mostrar, portanto, imparcialidade.

Ressaltamos que as escolhas léxico-gramaticais no texto apresentado na denúncia fortalecem a argumentação presente no enunciado do produtor para que as ações do acusado sejam interpretadas pelo juiz como intencionais e, portanto, passíveis de condenação.

Nas denúncias identificamos o constante uso de abreviaturas como é o caso de [fls]. para se referir a folhas, [art]. para artigo, [cod]. para código, entre outras, ressaltamos que todas as abreviaturas foram desenvolvidas na transcrição seguindo a norma de edição do PHPB. No entanto, o que mais chama atenção reside na ortografia de algumas palavras que se distinguem da forma como escrevemos atualmente, como é o caso de assignado, attribuições, facto, deshonestas, phisicamente, delicto, ella, sciente, réos, legaes, etc.

Durante a produção de uma denúncia, expunha-se seu objetivo central, sua razão de ser. Sempre que esse momento se fazia necessário pelo desenvolvimento do texto, utilizava-se uma fórmula composta pelo ato de fala de "tornar conhecido determinada ação criminal", por meio de uma narração que tem início com a expressão que ora se realizava como "pelo | facto delictuoso que:", com a variação "pelo fato delituoso que:", e ainda na forma "pelo facto criminoso que:", seguido dos dois pontos indicando que teria início o resumo narrativo. Para melhor contextualizar o leitor acerca de como essas expressões compunham as denúncias, mostraremos a seguir um excerto transcrito de uma denúncia:

[fl 1 frente] Ilustríssimo Senhor Doutor Juiz Substituto da 2a vara. A. Como pede, o Escrivão designa dia, hora para proceder-se á | das testemunhas|| Fortaleza, 18 de Fevereiro, 1911. | Gabriel Cavalcante. || O Promotor de Justiça desta Capital, | no desempenho de suas funcções, vem a-|presentar a Vossa Senhoria denuncia contra Julio | Nunes dos Santos, pelo facto criminoso que | passa a relatar: || No dia $1^{\circ}$ de Dezembro do anno pas-|sado por volta de 10 horas da manhã, na | rua Barão do Rio Branco, areias, o de-| nunciado, após um incidente de pequeno al-|cance moral com sua noiva Raymunda | Paulina da Silva, sacou de um rewolver, | e disparando um tiro, alvejou a cabeça da | inditosa rapariga, produzindolhe um feri-|mento grave, do qual veio a falecer no dia 5 do referido mez, conforme os autos de corpo de delicto 'e exame cadaverico de folhas. [..]

TEXTO 3 - Denúncia de ferimentos Fonte: APEC

A expressão 'pelo facto delictuoso que', utilizada para dar início ao processo narrativo que leva ao juiz o conhecimento acerca da motivação do delito cometido, é repetida em 10 textos de autores diferentes. Essa ocorrência demonstra que a escolha de inseri-la em sua petição vai depender da 


\section{REVISTA DA ABRALIN}

opção do autor do texto, portanto, não há regras para o uso dessa fórmula, cada promotor utiliza aquela que mais está acostumado a usar, por isso existem variações desta mesma expressão.

Em outros textos, mais precisamente em 12 denúncias, vemos o emprego de uma fórmula textual semelhante à anterior, por isso dizemos que ela é uma variação, que pode ser descrita como " $[\mathrm{x}]$ fato delituoso [y]", em que o [x] pode ser preenchido por "pelo"; "o"; "no" e "seguinte", no caso de textos do século XXI, e no [y] pode ser usado "que"; "seguinte"; "descrito"; ou ainda seguido de dois pontos [:], como podemos ver no quadro;:

\begin{tabular}{|l|l|l|}
\hline Pelo & \multirow{2}{*}{ fato delituoso } & que: \\
\cline { 1 - 1 } $\mathrm{O}$ & & seguinte: \\
\cline { 1 - 1 } No & & descrito: \\
\cline { 1 - 1 } Seguinte (Séc. XXI) & & $(:)$ \\
\hline
\end{tabular}

\section{QUADRO 4 - Distribuição da expressão de abertura} Fonte: Elaboração própria

A expressão adotada nas denúncias nos mostra também que aparece em textos de autores diferentes, mas que cumpre a mesma função no que se refere ao projeto de dizer da fórmula anteriormente descrita.

Acreditamos haver uma tendência que pode estar ligada ao estilo que o produtor empresta ao seu texto, uma vez que não existe apenas um modo de dizer dos crimes, pois encontramos uma terceira fórmula textual, "pelo facto criminoso que", que cumpre a mesma função das outras no que diz respeito à narração da motivação do delito e encontramos apenas quatro ocorrências.

Salientamos que nem todas as denúncias apresentavam tal forma textual; algumas não indicavam o início da narrativa, apenas continuavam o texto sem nenhuma indicação de limite entre unidades retóricas. Como ocorre no trecho a seguir:

[fl.1 frente] Ilustríssimo Senhor Doutor Juiz Municipal da 1a Vara de Fortaleza: || A. Recêbo a denuncia. Faça-se a citação do | denunciado para se vêr processar e julgar | e para o [ilegível] em dia [ilegível] || O Primeiro Promotor de Justiça da Capital vem, no uso de suas | atribuições legais e baseado no inquerito policial incluso, apresen-|tar a Vossa. Senhoria. Denuncia contra JOSÉ PAULO DA SILVA, brasileiro, na-|tural de Aracaty, deste Estado, estivador, casado, maior, residente á | rua Braga Torres, n. 483, alfabetisado. || Vivia na companhia do denunciado a sua cunhada MARIA ESTELA | DA SILVA, maior, pessôa de bons costumes, tendo então ele achado que | em vista disso Estela deveria obe[de]cer-lhe totalmente, chegando a | querer proibir sua cunhada de entreter palestras com suas amigas. [...]. 


\section{REVISTA DA ABRALIN}

No que diz respeito ao encerramento da peça inicial processual das denúncias coletadas, a forma textual que mais se repete é a que apontamos como 'requer que'

A fórmula textual "requer que" é o modo de enunciar mais usado pelos promotores para finalizar as denúncias. Do total de 46 textos, ela se repete em 13 denúncias abrangendo os dois séculos. Tal forma é bem característica do gênero devido ao projeto de dizer inerente tanto ao gênero quanto à forma textual, pois, para finalizar o documento, o promotor faz sua petição de acordo com o relato que fez e embasado na lei que determina que punição o infrator deve sofrer por ter cometido qualquer que tenha sido o delito criminoso. Apesar de aparecer em menos da metade do corpus, essa forma de texto mostra que a mudança não foi concretizada, porém demonstra que houve pelo menos uma sinalização para que uma possível mudança ocorresse, salientamos ainda que essa mudança não ocorreu por que não houve, de fato, uma substituição das formas.

Além das formas textuais encontradas anteriormente, outra fórmula textual que tomamos como tradição discursiva de encerramento e que se destaca nas peças acusatórias iniciais é a que tem início com a forma "e que se", seguida das formas verbais "ouçam" ou "observem".

No que se refere a esta tradição discursiva, ela é evocada e repetida sempre que o promotor de justiça deseja pedir a convocação das testemunhas, uma vez que, para a completa formação da culpa do acusado, torna-se necessário que se peça a inquirição das testemunhas arroladas por ele na denúncia. Dessa forma, o verbo "pedir" é bastante recorrente nas denúncias e raramente é conjugado em primeira pessoa, sendo por diversas vezes utilizado na forma impessoal, na forma "pede-se".

A forma verbal repete-se em 15 textos de autores diferentes nas denúncias, seguida, na maioria das vezes pela conjunção conclusiva "portanto", e pelo pronome relativo "que", o que evidencia que o promotor se dirige a seu enunciatário com a intenção conclusiva de fazer um pedido após narrar as informações criminais embasadas na lei.

É esperado observarmos que a língua, com o passar do tempo, sofra modificações. Essas modificações também são percebidas nos usos que são feitos. Em denúncias registradas no início do século XXI, identificamos alguns traços de mudança e vestígios de permanência quanto à norma linguística. De imediato, percebemos que os promotores mantiveram o emprego da norma culta, pois a prática discursiva não mudou e continua requerendo esta variedade da língua, embora não seja raro encontrar discrepâncias sobretudo de natureza ortográfica.

Percebeu-se, no decorrer da análise, que o conteúdo das denúncias do século XXI tornou-se mais extenso devido ao acréscimo de informações prestadas no inquérito policial, fato este que não constava nas denúncias produzidas no século passado. Assim, os promotores passaram a utilizar a linguagem cada vez mais a seu favor no momento de construir sua argumentação perante o juiz ordinário, pois, além de relatar o crime, eles também justificam mais detalhadamente a razão do oferecimento da denúncia, diferentemente da forma como faziam os promotores do século XX, pois, enquanto aqueles mencionavam quais leis haviam sido infringidas, os contemporâneos fazem um relato minucioso acerca da ação criminosa na tentativa de suceder positivamente na petição.

Abaixo podemos averiguar como essa justificativa de se oferecer a denúncia é extensa: 


\section{REVISTA DA ABRALIN}

A EXORDIAL LIBELÁRIA E A INCIDÊNCIA || DE UMA EXCLUDENTE DE ILICITUDE || Indagar-se -ia: Estando pois, o Representante do Ministério Público, diante de uma excludente de ilicitude, mormente a legitima defesa, | não poderia requer o arquivamento das peças de informação, pedindo a absolvição do pretenso indiciado? || "Pode o promotor de justiça no Plenário do Júri pedir a absolvição do réu, sem que o fato constitua nulidade. Dos termos dos artigos. 471 | e 564, n. . III, "l", do Código de Processo Penal não se infere que o representante do Ministério Público seja sempre obrigado a acusar, | ainda contra sua consciência, desde que não encontrou elementos para refutar a defesa" (RT 496/265). || Contrariando a todos s, devemos confessar que o assunto não é tranqüilo entre os doutrinadores. || O Promotor de Justiça, no momento da denúncia, não pode presumir que o réu é inocente, e conseqüentemente deixar de oferecê-la, | justamente porque estaria retirando o direito do próprio réu de ver-se julgado por seu juiz previamente competente, que é o juiz togado | - competência singular -, o Tribunal - competência originária -, ou juiz popular - competência do Tribunal do Júri. Deve deixar que o seu | verdadeiro julgador faça as vezes do julgamento, tendo incidência o in dubio pro reo quando da sentença final, ao analisar a prova $(\mathrm{O} \mid$ in dubio pro reo também tem incidência na interpretação da lei, se o intérprete não conseguir descobrir a intenção da lei depois da | utilização de todos os meios interpretativos. Damásio Evangelista de Jesus, Direito Penal, Volume.1, página. 37, diz, citando Asua e Alípio | Silveira: "se a vontade da lei não se forma nítida, se não chegar o juiz a saber se a lei quis isso ou aquilo, ou se nem ao menos | consegue determinar o que ela pretende, deverá seguir a interpretação mais favorável ao réu (desde que usados todos os meios | interpretativos)" || Acerca do tema, nos reportamos as lições do professor Romeu de Almeida Salles Junior, em seu festejado livro publicado pela editora jalovi Inquérito policial e ação penal: || Diz o Representante do parquet Bandeirante: || "Em nosso trabalho intitulado " Do crime"(S.Paulo, Brasilivros,1980,p.44) formulamos uma pergunta: pode haver tipicidade sem que | haja antijuricidade" ? .É evidente que a resposta é afirmativa, e no trabalho mencionado citamos, como exemplo, a excludente do | Estado de necessidade, prevista no art 19I, do Código Penal. || A lançado ás águas do mar por ocasião de um naufrágio, consegue apoiar-se numa taboa. Quando ali se encontrava B, que também se / achava no navio, busca apoio na mesma tábua. Esta não resiste ao peso de ambos e irá ao fundo provocando a morte a morte dos dois | náufragos.. || $\mathrm{A}$, par preservar a sua vida, investe contra $\mathrm{B}$, matando- ${ }^{\circ} \mathrm{Com}$ isso consegue a tábua para si, safando-se com vida do desastre. || Athaíde Monteiro da Silva, Procurador -Geral da Justiça do Estado de mato grosso e na época Presidente da Associação Mato - | grossessense do Ministério Público, publicou n Revista Justitia da APMP(A|ssociação paulista do Ministério Público),, falando sobre o | rigorismo técnico processual, do qual aduzimos nossa libelaria peça prefaciante, nos remete o seguinte comentário, que ,por interessante | transcrevemos in verbis: || Não é defeso ao Ministério em recebendo os || De inquérito policial ou conhecendo de || Elementos outros de informação, deixar de || exercer o "Jus denunciandi, se se \|| convencer, fundamentalmente, de que o indiciado \| agira sob o pálio da legitima defesa"(pág. 93) || Como afirmamos anteriormente, o agente da pretensão punitiva, em situações análogas ao caso sub lite, fica atrelado ao formalismo | técnico processual em cumprimento do andamento constitucional do tradicional Juízo natural crimes dolosos contra a vida. || A ação física do tenente David Serra Nóbrega é cristalina de legitima defesa, quando arriscando a sua própria vida, atirou em dois | marginais perigosos, que, com certeza, se assim, não fizesse, este dois mórbidos e indesejáveis indivíduos ceifaria a 


\section{REVISTA DA ABRALIN}

vida do brilhante | militar e de sua noiva, ficando a nossa milícia desfalcada de homem tenacidade e coragem. || Qualquer estudante de direito, não importa o nível, amoldaria a conduta do Tenente Davi Serra Nóbrega como excludente de legítima defesa || Júri. "A lei assegura aos acusados ampla defesa, ainda quando o defensor transpõe os limites da ética e da moral" (Rel. Lívio da |Fonseca Prates, RJTJRS, 36/95).

\section{TEXTO 5 - Denúncia de assalto} Fonte: APEC

No excerto acima, verificamos que o promotor escreve este trecho da denúncia demonstrando que constrói seu discurso tentando justificar sua denúncia, por estar sempre na defensiva de que se faz necessário oferecê-la, visto que o alvo é um oficial da polícia militar que reagiu a um assalto e matou os assaltantes. O enunciador faz referência a obras escritas por juristas que justificam a legítima defesa para fazer valer seu discurso por meio da argumentação por autoridade. A utilização da linguagem em termos técnicos parece demonstrar que há uma preocupação maior em atingir o destinatário e impressionar através do discurso.

No final do texto ainda é possível perceber como o promotor procede para o encerramento de sua petição. Abaixo vemos que não se diferencia do que já expusemos acima quando tratamos de denúncias do início do século XX:

|| Deste modo e porque o denunciado praticou o ato, amoldado ao aquetipo semântico do art 121 do do Código Penal Brasileiro, é contra | ele oferecida a presente peça vestibular acusatória, iniciadora da ação penal pública incondicionada, esperando o agente da pretensão | punitiva, que Vossa.Excelência a receba, ordenando a citação do acusado par os atos e termos do processo, até final julgamento, e |, posteriormente, levado a'tribunal do júri.

\section{TEXTO 6 - Denúncia de assalto Fonte: APEC}

Essas constatações nos remetem a Koch (1997), que defende que os enunciados, além das regras da língua histórica, também seguem regras de modelos textuais, que são as tradições discursivas. Portanto, percebemos que o gênero ainda mantém muito do que era produzido no início do século XX com o emprego da variedade culta, fórmulas de abertura e encerramento, salvo a introdução de latinismos, vocabulário especializado, informações apuradas pela investigação policial para ajudar na condução argumentativa. 


\section{REVISTA DA ABRALIN}

\section{Considerações finais}

Ao observarmos o desenvolvimento de uma tradição discursiva, no caso, a denúncia, vimos como os gêneros estão suscetíveis às mudanças, mesmo aqueles que julgamos mais rígidos.

A categoria aqui analisada torna possível reconhecer as expressões que evocam as tradições de abertura e de encerramento das denúncias. Nossa análise evidenciou aspectos linguísticos que compõem a denúncia, como as expressões que caracterizam a abertura e o encerramento da peça processual.

As denúncias produzidas até meados do século XX seguiam os mesmos padrões formais e discursivos, tanto que as fórmulas de abertura e encerramento se repetiam e evocavam uma mesma tradição discursiva em diversas denúncias, no entanto, com o passar dos anos, um novo século adentrou e marcou uma nova fase do judiciário. Agora surgia uma nova forma de se dar início à petição, com recursos mais variados, e não menos polêmicos, de uso da linguagem, como referências a obras de autores especializados, emprego de expressões latinas para demarcar o discurso, expressões arcaicas tão criticadas pela sociedade leiga no assunto.

A linguagem utilizada pela Justiça é uma linguagem pública, social e cívica. Os operadores que utilizam essa linguagem não falam só para si, sobre eles recai o dever de conservar e aprimorar a capacidade de interlocução com o auditório mais amplo que é a sociedade. Neste universo tão particular e ao mesmo tempo tão aberto, falar ou escrever nunca é um ato banal, pelo contrário, é a construção da argumentação, a utilização da linguagem como instrumento de racionalidade e de convencimento.

Ainda que de forma breve, os resultados nos permitiram apresentar sucintamente as transformações pelas quais a denúncia passou no curso de sua trajetória. Os resultados foram obtidos graças ao estudo de cunho diacrônico, pois nos ajudaram a nos debruçar sobre essa tradição discursiva em busca de investigar o que antes era completamente desconhecido e distante da realidade com que víamos o gênero denúncia.

A linguagem empregada em denúncias que remontam ao início do século XX demonstra ser bem mais acessível, do ponto de vista de ser entendida por especialistas e leigos, que a empregada nos dias atuais; aquela forma de escrever simples e mais sucinta foi perdendo seu espaço para uma escrita mais elaborada. Essa mesma linguagem passou a ser utilizada de forma distinta pelos representantes da lei em função das novas demandas sociais, agregou-se a ela expressões latinas, vocabulário mais rebuscado, riqueza na apresentação dos detalhes das informações colhidas pela investigação, o fato é que a linguagem cumpriria bem sua função na interação entre os interlocutores, isto é, entre o Promotor e o Juiz.

Essa mudança interferiu diretamente na extensão das denúncias. Até 1950, os textos eram escritos em até no máximo 4 laudas; a partir dos anos de 1990, por exemplo, as petições iniciais costumavam ser escritas em até 8 laudas, visto que os promotores, atendendo as mudanças sociais, como é o caso da chegada da informática no judiciário, passaram a pormenorizar o modo como o crime ocorreu, a fim de evitar o rito sumário e, consequentemente, o conteúdo transmitido pela peça processual tornou-se mais extenso. 


\section{REVISTA DA ABRALIN}

É evidente que, em nossa análise, percebemos que o aspecto da norma que caracteriza o gênero não se manifesta exatamente do mesmo modo ao longo dos séculos XX e XXI. É justamente essa a contribuição do olhar para os textos de sincronias passadas, pois nos permite mostrar as transformações observadas no interior de um gênero. Essa contribuição se deu também para mostrar que uma característica tida como marcante naquela prática discursiva é resultado de uma construção histórica, além de evidenciar que a forma como conhecemos um gênero em nosso tempo pode não ter se manifestado sempre da mesma forma.

Por último e não menos importante, salientamos a importância das ferramentas criadas para análise de corpora por exercerem papel muito importante na pesquisa linguística, em especial, nesta. Sem dúvida alguma a utilização do concordanciador foi decisiva no momento de contabilizar as ocorrências. Pudemos melhor visualizar as frequências com que uma expressão se repetia no texto e se configurava como uma tradição discursiva.

\section{REFERÊNCIAS}

ALBERTS-FRANCO, Cristina. Linguística de corpus e terminologia bilíngue: o programa AntConc e a extração de termos em alemão. In: The ESPecialist, São Paulo, vol. 36, nº 2, p.182-202, 2015. Disponível em:

https://revistas.pucsp.br/index.php/esp/article/download/23977/17279. Acesso em: 10 set. 2020.

ARAÚJO, Júlio César R. Os chats: uma constelação de gêneros na internet. Tese (Doutorado em Linguística) -

Centro de Humanidades, Universidade Federal do Ceará, Fortaleza, 2006.

BAKHTIN, Mikhail. Estética da criação verbal. Tradução Paulo Bezerra. São Paulo: Martins Fontes, 2011.

BAKHTIN, Mikhail. Problemas da poética de Dostoievski. Tradução Paulo Bezerra. 3. ed. Rio de Janeiro: Forense Universitária, 2005.

BELLOTTO, Heloisa Liberalli. Como fazer análise diplomática e análise tipológica de documento de arquivo. São Paulo: arquivo do estado, imprensa oficial, 2002. 120 p. (PROJETO COMO FAZER, vol. 8).

COSERIU, Eugenio. Lições de linguística geral (edição revista e ampliada pelo autor). Rio de janeiro: Ao Livro Técnico, 1980.

KABATEK, Johannes. Cómo investigar las tradiciones discursivas medievales? El ejemplo de los textos jurídicos castellanos. In: JACOB, D.; KABATEK, J. (Ed.) Lengua medieval y tradiciones discursivas em la Península Ibérica. Frankfurt am Main: Vervuert/Madrid: iberoamericana, 2001.p. 97-132.

KABATEK, Johannes. Tradições discursivas e mudança linguística. In: Tânia Lobo / Ilza Ribeiro / Zenaide Carneiro / Norma Almeida (Orgs.): Para a História do Português Brasileiro, Vol. VI: Novos dados, novas análises, Tomo II, Salvador, Bahia: EDUFBA 2006, 505-527.

KOCH, Peter. Diskurstraditionen: zu ihrem sprachtheoretischen Status und ihrer Dynamik. In: FRANK, B., HAYE, T., TOPHINKE, D. (Hrsg.). Gattungen mittelalterlicher Schriftlichkeit. Tübingen: Narr, 1997. p.43-79. Tradições discursivas: de seu status linguístico teórico e de sua dinâmica. Tradução: Profa. Dra. Alessandra Castilho da Costa. 


\section{REVISTA DA ABRALIN}

KOCH, Peter; ÖESTERREICHER, Wulf. Lingua hablada em la Romania: Español, Francês, Italiano. Madrid: Editorial Gredos, 2007.

LONGHIN, Sanderléia Roberta. Tradições discursivas: conceito, história e aquisição. São Paulo: Cortez, 2014.

POSSATO, Maria Carmem Guimarães. As interfaces da linguagem jurídica. Âmbito Jurídico, v. Ano XV, p. 99, 2012. Disponível em: http://www.ambitojuridico.com.br/site/?n_link=revista_artigos_leitura\&artigo_id=11494 Acesso em: 8 set. 2020.

ZAVAM, A. S. Por uma abordagem diacrônica dos gêneros do discurso à luz da concepção de tradição discursiva: um estudo com editoriais de jornais. Tese (Doutorado em Linguística) - Programa de Pós-Graduação em Linguística, Universidade Federal do Ceará, Fortaleza, 2009. 